\title{
Prangos pabularia Bitkisinin Antioksidan ve Antimikrobiyal Özelliklerinin Belirlenmesi
}

\author{
Funda TURHAN AYKANAT ${ }^{1}$, İbrahim Halil ŞAHİN ${ }^{2}$, Fatih Çağlar ÇELIKKEZEN ${ }^{3 *}$ \\ Şükrü HAYTA ${ }^{4}$ \\ ${ }^{1}$ Bitlis Eren Üniversitesi, Fen Bilimleri Enstitüsü Kimya ABD, 13000, Bitlis \\ ${ }^{2}$ Bitlis Eren Üniversitesi, Sağllk Hizmetleri M.Y.O., Tıbbi Hizmetler ve Teknikler Bölümü, 13000, Bitlis \\ ${ }^{3}$ Bitlis Eren Üniversitesi, Fen Edebiyat Fakültesi, Kimya Bölümü, 13000, Bitlis \\ ${ }^{4}$ Bitlis Eren Üniversitesi, Mühendislik Mimarlık Fakültesi, Çevre Mühendisliği Bölümü, 13000, Bitlis \\ (ORCID:0000-0002-5909-6938) (ORCID:0000-0003-4817-2947) \\ (ORCID:0000-0001-5489-7384) (ORCID: 0000-0001-8304-5236)
}

\begin{abstract}
$\ddot{O} z$
Tibbi ve aromatik bitkiler, tarih öncesi çağlardan bu yana tedavi edici özelliklerinin yanında gıda üretiminde tat ve aroma katmak amacıyla yaygın olarak kullanılmaktadır. Son yıllarda özellikle yurt dışında büyük ilgi gören bitkilerle tedavi yöntemi, yurdumuzda da önem kazanmaya başlamıştır. Sunulan çalışma Bitlis ilinde doğal olarak yetişen Prangos pabularia bitkisinin antioksidan ve antimikrobiyal özelliklerini incelemek amaciyla planlandı. Çalışmada kullanılan P. pabularia bitki örnekleri Bitlis Kambos Dağı'ndan toplandı. Bitkinin yaprak ve meyvelerinin uçucu yağları su distilasyonu ile elde edildi. Antioksidan özelliklerinin belirlenmesi için DPPH metodu kullanıldı. Bitki meyvelerinin ve yapraklarının antioksidan aktiviteleri sırasıyla $\% 28.70$ ve $\% 25.54, \mathrm{IC}_{50}$ değerleri ise $15.43 \mu \mathrm{g} / \mathrm{ml}$ ve $16.73 \mu \mathrm{g} / \mathrm{ml}$ olarak saptandı. Antimikrobiyal aktivite ise disk difüzyon metodu kullanılarak belirlendi. Bitki meyvelerinden elde edilen uçucu yağlar Proteus mirabilis ve Enterobacter aurogenes standart suşlarına karşı zayıf antibiyotik etki gösterdi. Yapraklardan elde edilen uçucu yağlar ise bakteri ya da mantar suşlarına karşı herhangi bir antibiyotik etki göstermedi.
\end{abstract}

Anahtar kelimeler: Prangos pabularia, Apiaceae, Antioksidan, Antimikrobiyal, Bitlis.

\section{Detecting of Antioxidant and Antimicrobial Specifications of Prangos pabularia}

\begin{abstract}
Medicinal and aromatic plants have been used extensively since prehistoric times in order to give taste and aroma in food production. In recent years, the treatment method with plants of great interest especially in abroad, has started to gain importance in our country. The present report was planed to determine antioxidant and antimicrobial properties of Prangos pabularia which growed naturally in Bitlis city. The samples of P. pabularia plant were picked up from Kambos Mountain in Bitlis. Essential oils of leaves and fruits of plant obtained by water distillation. To determine antioxidant properties, DPPH method was used. Antioxidant activities of fruits and leaves of the plant were determined as $28.70 \%$ and $25.54 \%, \mathrm{IC}_{50}$ values detected as $15.43 \mu \mathrm{g} / \mathrm{ml}$ and 16.73 $\mu \mathrm{g} / \mathrm{ml}$ respectively. Antimicrobial activity was detected by disc diffusion method. The essential oil of fruits of plant showed thin antibiotic activity against Proteus mirabilis and Enterobacter aurogenes. The essential oil of leaves of the plant did not show antibiotic effect against any bacterial or fungi strain.
\end{abstract}

Keywords: Prangos pabularia, Apiaceae, Antioxidant, Antimicrobial, Bitlis

"Sorumlu yazar: celikezen@ gmail.com

Geliş Tarihi: 31.01.2019, Kabul Tarihi: 28.05.2019

Bu çalışma Funda TURHAN AYKANAT'ın aynı isimli yüksek lisans tezinden türetilmiştir. 


\section{Giriş}

Apiaceae (Umbelliferae) familyası ilk olarak 16. yüzyılda tipik çiçeklenme şekli ile botanikçilerin dikkatini çekmiştir. Büyük çoğunluğu 1lıman bölgelerde yayılış gösteren Apiaceae familyası bugün dünyada bilinen 464 cins ve yaklaşık 3700 türe sahip geniş, kozmopolit bir familyadır [1]. Apiaceae familyası, beslenme, sağlık, meşrubat, baharat, boyama, kozmetik, güzel koku ve endüstriyel amaçlarla kullanılan birçok bitkiyi ihtiva eder. Etnomedikal olarak bu aileye ait bazı bitkiler hormonal, sindirim sistemi, üreme ve solunum sistemi hastalıklarında ev yapımı ilaçlar olarak kullanılmaktadır [2].

Prangos (Umbelliferae) cinsi, dünya genelinde 28 türü içermektedir. En önemli çeşitlenme merkezi İran-Turan fitocoğrafik bölgesidir. Türkiye'de yayılış gösteren takson sayıs1 19 olup, bunlardan 11 tanesi ülkemiz için endemiktir. Türkiye'de Prangos cinsi temsilcileri halk tıbbında tonik olarak, harici kanamayı durdurmak ve yara izlerini iyileştirmek için (dış uygulama) kullanılmaktadır. Hindistan'da, $P$. pabularia 'nın kökleri adet hızlandırıcı olarak bilinirken, tüm bitki sudaki salyangozları öldürmek için kullanılmaktadır. Bunlara ek olarak, $P$. pabularia meyvelerinin uyarıcı ve antiflatulen olarak kullanıldığ bildirilmiştir [3]. Bunlara ek olarak, Koul ve Thakur (1978) $P$. pabularia Lindl.'dan elde edilen esansiyel yağın içeriğinde; kamfen, D-3-karen, limonen, $\beta$-fellandren, terpinolen, kafur, karvon, $\beta$ - karyofillen, $\beta$ ve $\gamma$ - elemen, $\beta$-selinen, sitronellil asetat, ödesmol, geranil asetat, elemol, b- karyofillen oksit, mirsen ve $\alpha$-pinen olduğu saptanmıştır [4].

Günümüzde doğal olmayan ilaçların kullanımı sonucu oluşan önemli yan etkiler ve bunların sebep olduğu tıbbi ve ekonomik problemler bitkisel tedaviyi tekrardan gündeme hale getirmiştir [5]. Sentetik antioksidan ve antimikrobiyal maddelerin güvenilir olup olmamaları ile alakalı endişelerin artması, doğal hammadde kaynakları üzerine yapılan çalışmaları artırmış ve yüksek oranda antioksidan ve antimikrobiyal özellik gösteren bileşikleri ihtiva etmesinden dolayı tıbbi ve aromatik bitkiler alanında yapılan araştırmalar artış göstermiştir. Buna paralel olarak, dünyanın farklı yerlerinde yetişen ve özellikle medikal özelliklerinden faydalanılan birçok bitkinin antioksidan ve antimikrobiyal aktiviteleri belirlenmiştir [6-9].

Bu bilgiler 1şı̆̆ında, sunulan çalışma ile Bitlis ilinde doğal olarak yetişen Parangos pabularia bitkisinin antioksidan ve antimikrobiyal özelliklerini incelemek amaçlandı.

\section{Materyal ve Metot}

\subsection{Bitki Örneklerinin Toplanması ve Uçucu Yağların Elde Edilmesi}

P. pabularia bitkisi Bitlis İlinde Kambos Dağı adı verilen bölgede $\left(38^{0} 32^{1} 41.5^{11} \mathrm{~K} 42^{0} 01^{1} 23.9^{11} \mathrm{D}\right)$ doğal yaşama alanlarından 2017 yılının Temmuz ayında toplandı. Bitki örnekleri çalışılıncaya kadar uygun şartlarda saklandı. Bitkinin toplandığı alan kayalık ve yamaç kenarlarıdır. Yükseklik 2200-2400 m. civarındadır. Bitkinin bilimsel teşhisi BEÜ MMF Çevre Mühendisliği Öğretim Üyesi Doç. Dr. Şükrü HAYTA tarafindan yapıldı (SH 5025).

$P$. pabularia bitkisine ait meyve ve yapraklar kurutulduktan sonra 100'er gram alınarak Clevenger apartı ile 3 saat süreyle hidrodistilasyona tabi tutuldular. Elde edilen uçucu yağlar uygun şartlarda deney gününe kadar saklandı.

\subsection{Antioksidan Özelliklerin Belirlenmesi}

\subsubsection{DPPH Metodu}

Farklı miktarlarda bitki ekstrelerinden $1.5 \mu \mathrm{L}-40 \mu \mathrm{L}$ arasında değişen miktarlarda kullanılarak etanol de çözünmüş $0.4 \mathrm{~mL}, 0.5 \mathrm{mM}$ DPPH çözeltisine eklendi ve son hacim $2 \mathrm{~mL}$ olarak hazırlandı. Solüsyonlar iyice karıştırıldıktan sonra oda sıcaklığında, karanlıkta 30 dakika bekletildi. Blank numune olarak etanol kullanıld. Kontrol numunesi, $1 \mathrm{~mL} 0.5 \mathrm{mM}$ DPPH etanol ile (1:4) seyreltilerek hazırlandı. Absorbans düzeyleri $517 \mathrm{~nm}$ 'de belirlenerek \% inhibisyon değeri aşağıda verilen formül yardımı ile tespit edildi [10].

$$
\mathrm{I} \%=\left[\left(\mathrm{A}_{\mathrm{kontrol}}-\mathrm{A}_{\text {örnek }}\right)\right] / \mathrm{A}_{\text {kontrol }} \mathrm{X} 100
$$




\subsection{Antimikrobiyal Aktivite Tayini}

Bitki ekstresi örneklerinin antibiyotik etkisi, S. aureus (ATCC 33862), E. aurogenes (ATCC13048), P. mirabilis (ATCC 7002), Enterococcus faecalis (ATCC 29212), Candida tropicalis (RSKK), Eschrichia coli (ATCC35218), Pseudomonas aeruginosa (ATCC27853), Candida albicans (ATCC 90028), Acinetobacter baumannii standart suşları kullanılarak yapıldı. Pozitif kontrol olarak E. aerogenes, P. mirabilis, E.coli, P. aeroginosa standart suşları için Seftazidim, C. Tropicalis ve $C$. albicans standart suşları için Cycloheximide, S. aureus, A. baumanni standart suşları için Ciprofloksasin ve E. faecalis standart suşu için İmipenem standart diskleri kullanıldı.

\subsubsection{Disk Difüzyon Metodu}

Antimikrobiyal aktivite disk difüzyon metoduna göre çalışıldı [11]. Bakteri izolatları Mueller Hinton Broth (OXOID), mantar suşları ise SD Broth (DIFCO) sıvı besiyerine ekilerek $35 \pm 2^{\circ} \mathrm{C}$ 'de 24 saat inkübasyonla aktifleştirildi ve yoğunlukları MCFarland 0.5' e $(108 \mathrm{CFU} / \mathrm{mL})$ göre ayarlandı. [12].Bakteriler Mueller Hinton Agar (OXOID), maya mantarı Sabouraud Dextrose Agar (OXOID) besiyerlerine $100 \mu \mathrm{l}$ bırakılarak cam baget ile sürülerek kuruması için 15 dakika beklendi. $25 \mu \mathrm{l}$ bitki ekstreleri $6 \mathrm{~mm}$ çaplı steril standart disklere emdirilerek kültür ortamına bırakıldı [12]. Sonrasında numuneler 24 saat süre ile $37^{\circ} \mathrm{C}$ sıcaklıkta inkübe edilerek inhibisyon çapları belirlendi.

\section{Bulgular ve Tartışma}

Kılıç (2008), uçucu yağların elde edilme yöntemlerini ve bu yöntemlerin avantaj ve dezavantajlarını araştırdığı çalışmasında, farmakoloji, kozmetik ve gıda endüstrisi gibi çeşitli kullanım alanlarına sahip olan esansiyel yağların, Romacılardan bugüne kadar değişik yollarla elde edildiğini belirtmiştir [13]. Çalışmada genellikle kullanılan yöntemlerin, destilasyon, su destilasyonu (HD), ekstraksiyon ve presleme olduğu bildirilmiş̧ir. Son yıllarda kullanılan Süperkritik sıvı ekstraksiyonu (SFE), mikrodalga ekstraksiyonu (MWE) ve kat1-faz mikroekstraksiyonunun (SPME) vb. ise daha modern yöntemler olduğu belirtilmiş̧ir [13]. Sunulan çalışmada P.pabularia bitkisinin yaprak ve meyvesinin uçucu yağ asitleri su distilasyonu yöntemi ile elde edildi.

$P$. pabularia bitkisinin yaprak ve meyvesinin uçucu yağ asitlerinin antioksidan özellikleri DPPH metodu kullanılarak belirlendi. DPPH radikal temizleme aktivitesi bitki ekstraktlarının antioksidant aktivitelerinin belirlenmesinde en çok kullanılan metotlardan biridir [14]. Yapılan çalışmada, P. pabularia'nın yapraklarından elde edilen uçucu yağlarının antioksidan etkisi \%25.54, meyvelerinden elde edilen uçucu yağların antioksidan aktivitesi ise $\% 28.70$ olarak saptandı. IC 50 değerleri ise sirasıyla $16,73 \mu \mathrm{g} / \mathrm{ml}$ ve $15,43 \mu \mathrm{g} / \mathrm{ml}$ olarak tespit edildi (Tablo 1 ).

Tablo 1. $P$. pabularia bitkisinin antioksidan aktivite değerleri

\begin{tabular}{|l|c|c|}
\hline Bitki Numunesi & \% İnhibisyon Değeri & IC $_{\mathbf{5 0}}$ Değeri $(\boldsymbol{\mu g} / \mathbf{m l})$ \\
\hline Yaprak & $\% 25,54$ & 16,73 \\
\hline Meyve & $\% 28,70$ & 15,43 \\
\hline
\end{tabular}

Elde edilen sonuçlara paralel olarak, yapılan bir çalışmada Konya bölgesinden toplanan dört Prangos türünün, herba, kök ve meyvelerinden elde edilen su ve metanol $(\mathrm{MeOH})$ ekstrelerinin antioksidan aktiviteleri ile total fenolik madde miktarları araştırılmış ve tüm örneklerin DPPH metodu ile yapılan analizlerinde zayıf antioksidan etki gösterdikleri belirlenmiştir. Aynı çalışmada $\mathrm{MeOH}$ ekstrelerinin TBA testinde sulu ekstrelere göre daha yüksek antioksidan aktivite gösterdikleri saptanmıştır [15]. Martins vd (2016) tarafından yapılan bir çalışmada Apiaceae ailesinden Pimpinella anisum L. (anise) and Coriandrum sativum L. (coriander) bitki tohumlarının antioksidan özellikleri araştırılmış ve anise'nin yüksek fenolik içeriğe sahip olduğu ve yüksek bir antioksidan özellik gösterdiği rapor edilmiştir [16]. Ülkemizde yetişen P. ferulacea (L.) Lindl.'in etanol ve metanol ile hazırlanan meyve özütlerinin antioksidan aktivitelerinin DPPH metodu kullanılarak incelendiği bir çalışmada ise bütün meyve özütlerinin zayıf antioksidan özellik gösterdiği saptanmıştır [17]. Benzer bir çalışmada, P. Feruleceae (L.) Lindl. (Apiaceae) ekstraktlarının antioksidan aktivite gösterdiği tespit edilmiştir [18]. 
İki endemik Prangos türü olan P. heyniae H. Duman \& M. F. Watson ve P. denticulata Fisch. \& Mey. kullanılarak yapılan bir çalışmada bitkilerin su ve metanol ekstraktlarının yüksek antioksidan aktivite gösterdikleri rapor edilmiştir [19]. Diğer bir çalışmada Oliveria decumbens Vent. (Apiaceae) bitkisinin tohum ve çiçeklerinin uçucu yağ asit kompozisyonu, toplam fenolik ve flavonoid yapısı daha sonra antioksidan aktivitesi DPPH metodu ile çalışılmıştır. Oliveria decumbens Vent.'nin çiçekli kısımlarının $\mathrm{IC}_{50}$ değeri $86.1 \pm 3.8(\mathrm{mg} / \mathrm{ml})$ tohumlarında bu oran $98.5 \pm 4.2(\mathrm{mg} / \mathrm{ml})$ olarak tespit edilmiştir [20]. Apiaceae ailesinden Heracleum persicum Desf, P. ferulacea (L.) Lindl, Chaerophyllum macropodum Boiss.'in antioksidan ektivitelerinin incelendiği başka bir çalışmada ise $\mathrm{IC}_{50}$ değeri sırasıyla $0.438,0.242$ ve $0.623(\mathrm{mg} / \mathrm{ml})$ olarak tespit edilmiştir [21].

Sunulan çalışmada, elde edilen saf uçucu yağların antimirobiyal özellikleri disk difüzyon metodu ile çalış1ldı. Evren ve Tekgüler (2011), gram negatif bakterilerin uçucu yağların antimikrobiyal etkilerine karşı gram pozitif bakterilere göre daha fazla direnç gösterdiğini ve bu direncin hücre duvarından kaynaklanabileceğini bildirmişlerdir [22]. Fakat yapılan çalışmada, gram negatif bakterilerin $P$. pabularia'nın meyvelerinden elde edilen uçucu yağlara karşı daha duyarlı olduğu tespit edildi. Yapılan araştırmada, P. pabularia'nın E. aerogenez ve P. mirabilis standart suşlarına karşı zayıf antibiyotik etkiye sahip olduğunu gösterdi (Tablo 2).

Tablo 2. P. pabularia yaprak ve meyvesinden elde edilen uçucu yağların antimikrobiyal etkileri

\begin{tabular}{|c|c|c|c|c|c|c|}
\hline \multirow{2}{*}{ Mikroorganizma } & \multicolumn{4}{|c|}{ Pozitif Kontrol Zon Çapı (mm) } & \multirow{2}{*}{$\begin{array}{c}\text { Yaprak } \\
\text { Zon } \\
\text { çapı } \\
\text { (mm) }\end{array}$} & \multirow{2}{*}{$\begin{array}{l}\text { Meyve } \\
\text { Zon } \\
\text { çapı } \\
\text { (mm) }\end{array}$} \\
\hline & $\begin{array}{c}\text { Seftazidim } \\
\text { Zon Çapı } \\
(\mathrm{mm}) \\
\end{array}$ & $\begin{array}{c}\text { İmipenem } \\
\text { Zon Çap1 } \\
(\mathrm{mm})\end{array}$ & $\begin{array}{c}\text { Cycloheximide } \\
\text { Zon Çap1 } \\
(\mathrm{mm})\end{array}$ & $\begin{array}{c}\text { Ciprofloksasin } \\
\text { Zon Çapı } \\
(\mathrm{mm})\end{array}$ & & \\
\hline E. aerogenes & 29 & & & & - & 10 \\
\hline S. aureus & & & & 32 & - & - \\
\hline P. mirabilis & 30 & & & & - & 13 \\
\hline E. faecalis & & 30 & & & - & - \\
\hline A.baumannii & & & & 30 & - & - \\
\hline E.coli & 29 & & & & - & - \\
\hline P. aeroginosa & 27 & & & & - & - \\
\hline C.albicans & & & 42 & & - & - \\
\hline C.tropicalis & & & 40 & & - & - \\
\hline
\end{tabular}

Elde edilen sonuçlara paralel olarak yapılan bir çalışmada, Özek vd. (2007) tarafindan yapılan bir çalışmada, $P$. pabularia Lindl. meyvesinden elde edilen uçucu yağların antimikrobiyal etkisi mikrodilisyon yöntemi ile çalışılmış ve bazı bakteriler üzerine zayıf antibiyotik etki gösterdiğini saptamışlardır [23]. Diğer bir çalışmada, P. uloptera DC. köklerinin diklormetan ekstraktlarının $S$. aureus ve $B$. subtilis'e yüksek antimikrobiyal etki gösterdiği bildirilmiştir [24]. Yakın zamanda yapılan bir çalışmada, Türkiye'de tanımlanmış yeni bir endemik tür olan Prangos hulusii'nin diklormetan ekstraktının 9 standart suş ve 6 adet kliniksel olarak izole edilmiş türler üzerine antibiyotik etki gösterdiği rapor edilmiştir [25]. Apiaceae ailesine ait olan Alepidea species, A. natalensis Wood \& Evans ve A. Amatymbica Eckl. \& Zeyh. türleri üzerine yapılan bir çalışmada, bitkilerinin petrol eteri, diklormetan, etanol (\%80) ve su ekstraktlarını antibakteriyel, antifungal, antiinflamatuar ve genotoksik etkilerinin araştırılmış ve A. natalensis bitkisinin kök-saplarına ait su ekstraktlarının B. subtilis, E. coli, Klebsiella pneumoniae ve $S$. aureus standart suşlarına karşı yüksek antibiyotik etki gösterdiği tespit edilmiştir (MIC $0.78 \mathrm{mg} / \mathrm{ml}$ ). Çalışmada, bitki yaprağının petrol eteri ve diklormetan ekstraktlarının gram pozitif bakteriler üzerine yüksek aktivite gösterdiği tespit edilmiştir [26]. Tada vd (2002) tarafından yapılan bir araştırmada ise P. pabularia'dan elde edilen kumarin türevlerinden bazılarının antibakteriyel aktiviteye sahip olduğu saptanmıştır [27]. Durmaz vd (2006) Prangos ferulacea (L.) nin metanol ekstraktının dört gram pozitif bakteri ve beş gram negatif bakteriye karşı antimikrobiyal aktivitesini disk difüzyon yöntemi ile çalışmışlardır. Çalışma sonuçlarına göre B. cereus, B. subtilis, $M$. luteus ve $S$. aureus için antimikrobiyal etki saptanırken $E$. coli, K. pneumoniae, S. enteritidis ve $S$. typhimuri'ye karşı herhangi bir etki gözlenmemiştir [28].

Yakın zamanda yapılan bir çalışmada, yine aynı aileden olan (Apiaceae) Ferulago trachycarpa bitkisinin sap ve köklerinin, n-hexane, diklormetan ve metanol ektraktlarının Stapylococcus aureus, S. epidermidis, E. coli, K. pneumoniae, P. aeruginosa, P. mirabilis ve 
Enterococcus feacalis bakteri suşları ile $C$. albicans, $C$. tropicalis ve $C$. parapsilosis mantar suşları üzerine de antimikrobiyal etki gösterdikleri rapor edilmiştir [29]. Almurabet (2018) yaptığı bir çalışmada, Malatya yöresinden toplanan $P$. pabularia ekstraktının $S$. infantis ve $P$. fluorescens'e karşı antimikrobiyal etki gösterdiği, B. subtilis, C. albicans E. aerogenes, E. coli, E. faecium, P. aeruginosa, S. enteritidis, E. faecalis, K. pneumoniae, S. epidermidis, S. aureus, S. typhimurium ve S. kentucky'e karşı ise göstermediğini bildirmiştir [3].

\section{Sonuç ve Öneriler}

Sonuç olarak, yapılan çalışma ile Bitlis ili çevresinden toplanan P. pabularia bitkisinin meyve ve yapraklarından elde edilen uçucu yağların zayıf antioksidan etki gösterdiği belirlendi. Bunun yanında E. aerogenez ve $P$. mirabilis standart suşlarına karşı zayıf antibiyotik etkiye sahip oldukları ilk kez saptand1.

\section{Teşekkür}

Katkılarından dolayı Bitlis Tatvan Devlet Hastanesi Mikrobiyoloji Laboratuvarı çalışanlarına teşekkür ederiz.

\section{Kaynaklar}

[1] Yilmaz G., Ayla K., Koyuncu M. 2016. Türkiye'de Yetișen Heptaptera Marg. Reuter (Apiaceae) Türlerinin Meyve Morfolojisi ve Anatomisi. Ankara Üniversitesi Eczacilık Fakültesi Dergisi, 40 (2): 26-42.

[2] Aćimović M.G., Kostadinović L.M., Popović S.J., Dojčinović N.S. 2015. Apiaceae Seeds As Functional Food. Journal of Agricultural Sciences, 60 (3): 237-246.

[3] Almurabet E.M.S. 2018. Apiaceae Familyasına Ait Bazı Türlerin Antimikrobiyal Aktivitesinin İncelenmesi. Yüksek Lisans Tezi, Kastamonu Üniversitesi Fen Bilimleri Enstitüsü, 136s, Kastamonu.

[4] Koul S.K., Thakur R.S. 1978. The Essential Oil of Prangos Pabularia Lindl. India Perfumer, 22 (4): 284-286.

[5] Özbek H. 2005. Cinsel ve Jinekolojik Sorunların Tedavisinde Bitkilerin Kullanımı. Van Tip Dergisi, 12 (2):170-174.

[6] Rojas R., Bustamante B., Bauer J., Fernandez I., Alban J., Lock O. 2003. Antimicrobial Activity of Some Selected Peruvian Medicinal Plants. Journal of Ethnopharmacology, 88 (2-3): 199-204.

[7] Salvat A., Antonacci L., Fortunato R.H., Suarez E.Y., Goday H.M. 2004. Antimicrobial Activity in Methanolic Extracts of Several Plant Species from Northern Argentina. Phytomed, 11 (2-3): 230-234.

[8] Chanwitheesuk A., Teerawutgulrag A., Rakariyatham N. 2005. Screening of Antioxidant Activity and Antioxidant Compounds of Some Edible Plants of Thailand. Food Chemistry, 92 (3): 491-497.

[9] Ivanova D., Gerova D., Chervenkov T., Yankova T. 2005. Polyphenols and Antioxidant Capacity of Bulgarian Medicinal Plants. Journal of Ethnopharmacology, 96 (1-2): 145150 .

[10] Cuendet M., Hostettmann K., Potterat O. 1997. Iridoidglucosides with Freeradicals Cavening Properties From Fagrea blumei, Helvatica Chimica Acta, 80 (4): 1144-1152.

[11] National Committee for Clinical Laboratory Standards (NCCLS). 1997. Performance Standards for Antimicrobial Disk Susceptibility Tests. Approved Standard M2A6.Wayne, Pa: National Committee For Clinical Laboratory Standards. 
[12] Barry A.L., Thornsberry C. 1985. Susceptibility Tests: Diffusion Test Procedures. In: Manual of Clin Microbiol for Microbiol Lennette,Edited by E.H., Balows A., Hausler W.J., Shadomy H.J., American Society for Microbiology, 978-987.

[13] Kılıç A. 2008. Uçucu Yağ Elde Etme Yöntemleri. Bartın Orman Fakültesi Dergisi, 10 (13): $37-45$.

[14] Tirzitis G., Bartosz G. 2010. Determination of Antiradical and Antioxidant Activity: Basic Principles and New Insights. Acta Biochimica Polonica, 57 (1): 139-142.

[15] Ahmed J., Güvenç A., Küçükboyacı N., Baldemir A., Coşkun M. 2011. Total Phenolic Contents and Antioxidant Activities of Prangos Lindl. (Umbelliferae) Species Growing in Konya Province (Turkey).Turkish Journal of Biology, 353-360.

[16] Martins N., Barros L., Santos-Buelga C., Ferreira I.C. 2016. Antioxidant Potential of Two Apiaceae Plant Extracts: A Comparative Study Focused on The Phenolic Composition. Industrial Crops and Products, 79: 188-194.

[17] Cesur C., Şenkal B.C., Yaman C., Uskutoğlu T., Koç M. 2017. Antioxidant Activity of Fruit Extracts of Prangos ferulacea (L.) Lindl. From Turkey. Iğdır Üniversitesi Fen Bilimleri Enstitüsü Dergisi, 7 (4): 249-256.

[18] Kafash-Farkhad N., Asadi-Samani M., Rafieian-Kopaei M. 2013. A Review on Phytochemistry and Pharmacological Effects of Prangos ferulacea (L.) Lindl, Life Science Journal, 10: 360-367.

[19] Öke-Altuntas F., Aslim B., Duman H., Gulpinar A.R., Kartal M. 2015. The Relative Contributions of Chlorogenic Acid and Rutin to Antioxidant Activities of Two Endemic Prangos (Umbelliferae) Species ( $P$. heynia and $P$. denticulata). Journal of Food Biochemistry, 39 (4): 409-416.

[20] Esmaeili H., Karami A., Maggi F. 2018. Essential Oil Composition, Total Phenolic and Flavonoids Contents, and Antioxidant Activity of Oliveria Decumbens Vent. (Apiaceae) At Different Phenological Stages. Journal of Cleaner Production, 198: 91-95.

[21] Çoruh N., Sağdıçoğlu Celep A., Özgökçe F. 2007. Antioxidant Properties of Prangos ferulacea (L.) Lindl., Chaerophyllum macropodum Boiss. and Heracleum persicum Desf. from Apiaceae Family Used as Food in Eastern Anatolia and Their Inhibitory Effects on Glutathione-S-transferase. Food Chemistry, 100 (3): 1237-1242.

[22] Evren M., Tekgüler B. 2011. Uçucu Yağların Antimikrobiyel Özellikleri. Elektronik Mikrobiyoloji Dergisi, 9 (3): 28-40.

[23] Özek G., Özek T., Işcan G., Başer K.H.C., Hamzaoglu E., Duran A. 2007. Comparison of Hydrodistillation and Microdistillation Methods for The Analysis of Fruit Volatiles of Prangos Pabularia Lindl. and evaluation of its antimicrobial activity. South African Journal of Botany,73 (4): 563-569.

[24] Razavi S.M., Zarrini G., Zahri S., Mohammadi S. 2010. Biological Activity of Prangos uloptera DC. Roots. A Medicinal Plant From Iran, Natural Product Research, 24 (9): 797-803.

[25] Tan N., Bilgin M., Tan E., Miski M. 2017. Antibacterial Activities of Pyrenylated Coumarins From The Roots of Prangos hulusii. Molecules, 22 (7): 1098, doi:10.3390.

[26] Mulaudzi R.B., Ndhlala A.R., Finnie J.F., Van Staden, J. 2009. Antimicrobial, AntiInflammatory and Genotoxicity Activity of Alepidea, Amatymbica and Alepidea Natalensis (Apiaceae). South African Journal of Botany, 75 (3): 584-587.

[27] Tada Y., Shikishima Y., Takaishi Y., Shibata H., Higuti T., Honda G., Ito M., Takeda Y., Kodzhimatov O. K., Ashurmetov O., Ohmoto Y. 2002. Coumarins and $\gamma$-pyrone Derivatives From Prangos pabularia: Antibacterial Activity and Inhibition of Cytokine Release. Phytochemistry, 59 (6): 649-654. 
[28] Durmaz H., Sagun E., Tarakci Z., Ozgokce F. 2006. Antibacterial Activities of Allium Vineale, Chaerophyllum Macropodum and Prangos Ferulacea, African Journal of Biotechnology, 5(19): 1795-1798.

[29] Dikpınar T., Süzgeç-Selçuk S., Çelik B.Ö., Uruşak E.A. 2018. Antimicrobial Activity of Rhizomes of Ferulago trachycarpa Boiss. and Bioguided Isolation of Active Coumarin Constituents, Industrial Crops and Products, 123: 762-767. 